3. Muir K.W., McCormick M., Baird T. et al (2011), "Prevalence, Predictors and Prognosis of Post-Stroke Hyperglycaemia in Acute Stroke Trials: Individual Patient Data Pooled Analysis from the Virtual International Stroke Trials Archive (VISTA)", Cerebrovascular Diseases Extra, 1(1), pp. 17-27.

4. Shimoyama T., Kimura K., Uemura J. et al (2014), "Elevated glucose level adversely affects infarct volume growth and neurological deterioration in non-diabetic stroke patients, but not diabetic stroke patients", European Journal of Neurology, 21(3), pp. 402-410.

5. Lindsberg P.J., Roine R.O. (2004),
"Hyperglycemia in Acute Stroke", Stroke, 35(2), pp. 363-364.

6. Garg R., Chaudhuri A., Munschauer F. et al (2006), "Hyperglycemia, Insulin, and Acute Ischemic Stroke", Stroke, 37(1), pp. 267-273.

7. Saposnik G., Gladstone D., Raptis R. et al (2013), "Atrial fibrillation in ischemic stroke: predicting response to thrombolysis and clinical outcomes", Stroke, 44(1), pp. 99-104.

8. Marik P.E., Bellomo R. (2013), "Stress hyperglycemia: an essential survival response!", Critical care (London, England), 17(2), pp. 305-305.

\title{
ĐÁNH GIÁ KẾT QUẢ ĐIỀU TRI TRĨ NộI CHẢY MÁU BẰNG THẮT VÒNG CAO SU QUA MÁY NộI SOI ỐNG MỀM
}

\section{TÓM TẮT}

Mục tiêu: Mục đích của nghiên cứu là đánh giá hiêu quả lâm sàng và biến chứng của phương pháp điểu trị không phấu thuật với trĩ mức độ trung bình (I, II và III) bằng phương pháp nội soi thắt vòng cao su (ERBL). Đối tượng và phương pháp: Tổng số nghiên cứu trên 34 bệnh nhân tuổi trung bình 45,7 tuổi được sử dung phương pháp ERBL bằng máy nôi soi ống mềm và bộ thắt vòng cao su dùng cho thắt tĩnh mạch thực quản, tất cả bệnh nhân được theo dõi đánh giá kết quả lâm sàng và biến chứng. Kết quả: Kết quả nghiên cứu có 16 bênh nhân trĩ nội đô I, 10 bênh nhân trĩ nội độ II, 8 bệnh nhân trĩ nội độ İII. Tất cả bênh nhân đều có trĩ chảy máu, 4(19\%) bểnh nhân có ngứa hậu môn và $10(47.6 \%)$ bệnh nhân có dấu hiêu sa búi trĩ đây lên được. Sau điều tri ERBL triệu chứng chảy máu được cải thiện ở 30(88.1\%) bệnh nhân. Tất cả bệnh nhân cần phải thực hiên điều trị 1 lần, hoặc 2 lần, số vòng trung bình sử dụng 2,9 vòng, triệu chứng đau sau thắt vòng là thường gặp $21(61.8 \%)$ bênh nhân, hâuu hết giảm nhe sau đó. Kềt luận: Phương pháp thắt vòng cao su có sử dụng máy nôi soi mềm là phương pháp dễ thực hiện, an toàn và hiệu quả trong điều trị bênh lý trĩ có triêu chứng.

Tư khóa: Trĩ, thắt vòng cao su, nội soi ống mềm.

\section{SUMMARY}

\section{RUBBER BAND LIGATION FOR TREATMENT OF BLEEDING INTERNAL HEMORRHOIDS USING FLEXIBLE GASTROSCOPY}

Objective: The purpose of this study was the evaluation of the efficacy, clinical outcome

\footnotetext{
${ }^{1}$ Trung tâm tiêu hóa gan mật bệnh viện Bạch mai ²Bênh viên đa khoa tỉnh Bắc Ninh Chịu trách nhiệm chính: Nguyễn Công Long Email: nguyenconglongbvbm@gmail.com Ngày nhận bài: 15.9.2021

Ngày phản biện khoa học: 10.11.2021

Ngày duyệt bài: 19.11.2021
}

\section{Nguyễn Công Long', Nguyễn Hanh Thiện ${ }^{2}$}

complications with non-surgical treatment for intermediate grade (I, II and III) by endoscopic rubber band ligation (ERBL). Subjects and methods: A total 34 patients of mean age 45.7 years were underwent ERBL technique with the aid of a gastroscopy and a kit of elastic rubber bands for esophageal varices. All the patients were follow up and were evaluated technical and clinical efficiency and complications. Results: The obtained results showed that sixteen patients had grade I hemorrhoids, 10 patients had grade II hemorrhoids and 8 patients had grade III hemorrhoids. All the patients were observed with anal bleeding, in which 4 patients $(19 \%)$ was observed with chronic complaints itching and 10 patients $(47.6 \%)$ were observed with prolapse. In particularly, The rectal bleeding and other symptoms were controlled with significantly fewer treatments ERBL had a significantly higher success rate 30 patients $(88.1 \%)$, all patients needed a minimum of 1 treatment and a maximum of 2 treatments, a median of 2.9 bands was used in the procedure. Pain after ligation tended to be more frequent in patients treated with the flexible endoscope $61.8 \%$ (21 patients) but most of the complications are considered of low magnitude, easily resolved. Conclusions: The rubber band ligation using the flexible gastroscopy method was proved to be a feasible with advantages maneuverability, safe and efficient for the treatment of symptomatic hemorrhoid disease.

Keywords: Hemorrhoids, Band ligation, Flexible gastroscopy.

\section{I. ĐĂT VẤN ĐỀ}

Trĩ là rối loạn hậu môn trực tràng hay gặp nhất ở người lớn, là hiên tượng các mach máu vùng hâu môn căng to dễ chảy máu, găp nhiều ở người lao động tĩnh tại, táo bón kéo dài và trên $90 \%$ số bênh nhân được soi trực tràng hay đại tràng được tìm thấy là có trĩ ở các đô khác nhau [1]. Điều trị bảo tồn được cân nhắc ở những 
bệnh nhân có các triệu chứng chảy máu vùng hậu môn hoặc sa búi trĩ có thể đẩy lên được và phân độ I, II, III. Các điều trị bao gồm liệu pháp tiêm xớ, thắt vòng cao su (ERBL), đông hồng ngoại, áp lạnh, điện nhiệt lưỡng cực [2, 3]. ERBL trở thành biện pháp điều trị nền tảng cho chảy máu và sa búi trĩ nội, và hiện nay là kĩ thuật khá cơ bản, an toàn và hiệu quả. Thắt búi trĩ được sử dụng rộng rãi như là một biện pháp khác cho điều trị trĩ nội có triệu chứng và đã thay thế phẫu thuật cắt búi trĩ trong $45 \%$ các ca. Chính vì thế chúng tôi tiến hành nghiên cứu này nhằm đánh giá hiệu quả lâm sàng bằng phương pháp thắt trĩ bằng vòng cao su với ống nội soi mềm.

\section{II. ĐỐI TƯợNG VÀ PHƯƠNG PHÁP NGHIÊN CỨU}

Đối tượng: Nghiên cứu 34 bệnh nhân được lựa chọn từ nhóm bệnh nhân mắc bệnh trĩ tới khám chuyên khoa tiều hóa và điều trị tại khoa tiêu hóa Bệnh viện Bạch Mai từ tháng 9/2018 đến tháng 5/2019. Về nội soi được chẩn đoán trĩ nội độ I, II, III với triệu chứng đi ngoài ra máu đở tươii. Tiêu chuẩn loại trừ các bệnh nhân không đồng ý tham gia nghiên cứu.

Phương pháp: nghiên cứu mô tả, tiến cứu, theo dõi dọc so sánh trước sau điều trị.

\section{* Chuẩn bị bệnh nhân (BN)}

- Trước điều trị BN không phải dùng thuốc gây mê hay gây tê.

- Thụt tháo cho BN đại tiện hết phân trước khi điều trị.

- Tư thế BN: Nghiêng trái.

* Chuẩn bị dụng cụ

- Máy nội soi đường tiêu hóa trên ống mềm

- Bộ vòng cao su dùng trong thắt tînh mạch thực quản

\section{* Kỹ thuâat ERBL}

- Vị trí thắt. Thắt trên đường lược

- Thao tác kĩ thuật. Khi ở trong trực tràng đèn soi được quặt ngược và từ đầu gần của trực tràng, búi trĩ lớn nhất được thắt đầu tiên. Đầu dây soi được áp vào búi trĩ đã chọn và được hút hoàn toàn vào nón thắt, bằng cách thắt vào gốc búi trĩ tại vị trí trên đường lược $0,7-1,5 \mathrm{~cm}$ để tránh đau sau thắt. Nếu cần thiết có thể thắt thêm búi thứ 2 hoặc thứ 3 và cũng tiến hành như trên.

- Dặn dò BN theo dõi

- Sau thủ thuật xong cho BN nghỉ 30 phút kiểm tra mạch, huyết áp.

- Hướng dấn BN ở nhà: nhịn đi ngoài 24h, uống nhiều nước, tránh táo bón

- BN được kiếm tra

Sau mỗi lần thắt trĩ BN được gọi điện đánh giá kết quả cầm máu, độ trĩ cũng như các biến chứng. Nếu còn chảy máu sẽ tiếp tục thắt cho đến khi hết triệu chứng chảy máu

Xử lý số liệu : Sau khi thu thập đầy đủ các số liệu, quá trình xử lý được làm trên máy tính với phần mềm xử lý số liệu SPSS 16.0, tính hệ số tương quan $r$, giá trị $P<0,05$ được xác định là mức khác biệt có ý nghĩa thống kê.

\section{KẾT QUẢ NGHIÊN CỨU}

Bảng 1. Đặc điểm lâm sàng nhóm bệnh nhân nghiên cứu

\begin{tabular}{|c|c|c|}
\hline Triệu chứng & $\begin{array}{c}\text { Bệnh } \\
\text { nhân }\end{array}$ & $\begin{array}{c}\text { Tỷ lệ } \\
(\mathbf{\%})\end{array}$ \\
\hline Ngứa rát hậu môn & 4 & 11,8 \\
\hline Sa búi trĩ & 10 & 29,4 \\
\hline Ngứa rát + sa búi trĩ & 7 & 20,6 \\
\hline Chảy máu đơn thuân & 13 & 38,2 \\
\hline Tổng & $\mathbf{3 4}$ & $\mathbf{1 0 0}$ \\
\hline
\end{tabular}

Nghiên cứu 34 bệnh nhân gồm 24 nam, 10 bệnh nhân nữ. Triệu chứng lâm sàng, tất cả bệnh nhân có triệu chứng chảy máu, triệu chứng đi kèm hay gặp nhất là sa búi trĩ chiếm $29,4 \%$, nhưng các búi trĩ đều đẩy lên được.

Bảng 2. Đặc điểm búi trĩ trên nội soi

\begin{tabular}{|c|c|c|c|c|}
\hline Độ trĩ & \multicolumn{2}{|c|}{ Số bệnh nhân } & $\begin{array}{c}\text { Số } \\
\text { lướng } \\
\text { búi trî́n }\end{array}$ & $\begin{array}{c}\text { Búi trĩ } \\
\text { trung bình } \\
\text { trên moột } \\
\text { bệnh nhân }\end{array}$ \\
\hline Độ I & 16 & 47.1 & 46 & 2.87 \\
\hline Độ̀ II & 10 & 29.4 & 30 & 3 \\
\hline Độ̉ III & 8 & 23.5 & 27 & 3.37 \\
\hline Tống Số & 34 & 100 & 103 & 3.02 \\
\hline
\end{tabular}

Số bệnh nhân có trĩ độ I là cao nhất chiếm $47.1 \%$ và có số búi trĩ trung bình trên 1 bệnh nhân là 2.87 .

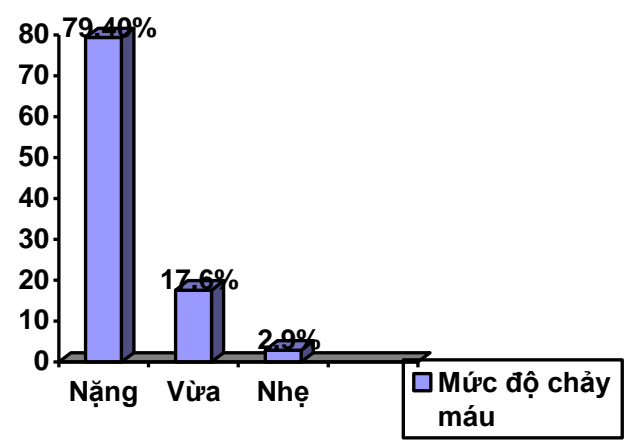

Biểu đồ 1. Mức độ chảy máu ở nhóm bệnh nhân nghiên cứu

Nhẹ: Khi đại tiện ra máu bám vào phân hoặc giấy về sinh.

Vừa: Khi đại tiện ra máu nhỏ thành giọt.

Nặng: Khi đại tiện ra máu chảy thành tia. 


\begin{tabular}{|c|c|c|c|c|c|c|}
\hline \multirow{2}{*}{\multicolumn{3}{|c|}{ Bảng 3. Thời gian thực hiện kỹ thuật }} & \multirow{3}{*}{\multicolumn{2}{|c|}{$\begin{array}{c}>10 \text { phút } \\
\text { Tổng số } \\
\end{array}$}} & \multirow{3}{*}{$\begin{array}{c}5 \\
34 \\
\end{array}$} & \multirow{3}{*}{$\begin{array}{l}14.7 \\
100 \\
\end{array}$} \\
\hline & & & & & & \\
\hline \multirow{2}{*}{$\begin{array}{l}\text { Thời gian thực hiện } \\
\text { thủ thuật ( phút) }\end{array}$} & \multirow{2}{*}{$\begin{array}{l}\text { Số bệnh } \\
\text { nhấn }\end{array}$} & \multirow{2}{*}{ Tỷ lệ } & & & & \\
\hline & & & \multirow{3}{*}{\multicolumn{4}{|c|}{$\begin{array}{l}29 \text { trên tổng số } 34 \text { bệnh nhân có thời gian } \\
\text { thực hiện thủ thuâat < } 10 \text { phút, có } 5 \text { trường hợp } \\
\text { thực hiện }>10 \text { phút. }\end{array}$}} \\
\hline$<5$ phút & 8 & 23.5 & & & & \\
\hline $5-10$ phút & 21 & 61.8 & & & & \\
\hline \multicolumn{7}{|c|}{ Bảng 4. Số lân thắt trĩ ở nhóm bệnh nhân nghiên cứu } \\
\hline \multicolumn{2}{|c|}{$\begin{array}{l}\text { Số bệnh } \\
\text { nhấn được thắn thắt }\end{array}$} & $\begin{array}{l}\text { Lân } \\
\text { Thứ } 1\end{array}$ & $\begin{array}{l}\text { Lân } \\
\text { thứ } 2\end{array}$ & $\begin{array}{l}\text { Tổng } \\
\text { số lần } \\
\text { thắt }\end{array}$ & \multicolumn{2}{|c|}{$\begin{array}{c}\text { Số lân thắt trung } \\
\text { bình ở } 1 \text { bệnh } \\
\text { nhân }\end{array}$} \\
\hline \multicolumn{2}{|c|}{ Số bệnh nhân trĩ độ I } & 16 & 1 & 17 & \multicolumn{2}{|c|}{1.06} \\
\hline \multicolumn{2}{|c|}{ Số bệnh nhân trĩ độ II } & 10 & 1 & 11 & \multicolumn{2}{|c|}{1.1} \\
\hline \multicolumn{2}{|c|}{ Số bệnh nhân trĩ độ III } & 8 & 0 & 8 & \multicolumn{2}{|c|}{1} \\
\hline \multicolumn{2}{|c|}{ Tổng số } & 34 & 2 & 36 & \multicolumn{2}{|c|}{1.05} \\
\hline
\end{tabular}

Các bệnh nhân ở nhóm trĩ nội độ I trung bình được thắt 1.06 lần, ở nhóm độ II trung bình 1.1 lần, ở nhóm trĩ độ III trung bình thắt 1 lần. Số lần thắt trung bình cho 1 bệnh nhân lầ 1.05 lần.

Bảng 5. Kêt quả câm máu trước và sau khi điều trị

\begin{tabular}{|c|c|c|c|c|c|c|c|}
\hline \multirow{2}{*}{$\begin{array}{c}\text { Kết quả câm máu } \\
\text { Mức độcháy máu }\end{array}$} & \multicolumn{2}{|c|}{ Tốt } & \multicolumn{2}{c|}{ Trung bình } & \multicolumn{2}{c|}{ Xấu } & Tổng số \\
\cline { 2 - 8 } & $\mathbf{n}$ & $\mathbf{\%}$ & $\mathbf{n}$ & $\mathbf{\%}$ & $\mathbf{N}$ & $\mathbf{\%}$ & \\
\hline Nặ̆ng & 21 & 77.8 & 2 & 7.4 & 4 & 14.8 & 27 \\
\hline Vừa & 6 & 100 & 0 & 0 & 0 & 0 & 6 \\
\hline Nhẹ & 1 & 100 & 0 & 0 & 0 & 0 & 1 \\
\hline
\end{tabular}

Nhóm bệnh nhân chảy máu mức độ vừa và nhe đạt kết quả cầm máu tốt là $100 \%$.

Các biến chứng chủ yếu là đau sau thắt 21(61.8\%) bệnh nhân, hầu hết giảm nhẹ sau đó

\section{BÀN LUẬN}

Nhóm bệnh nhân trong nghiên cứu của chúng tôi có độ tuổi trung bình là 45,1 $\pm 15,7$ tuổi. Tuổi trung bình trong nhóm bệnh nhân của chúng tôi thấp hơn của tác giả V. S. Iyer [4]. Triệu chứng lâm sàng, tất cả bệnh nhân có triệu chứng chảy máu, triệu chứng đi kèm hay gặp nhất là sa búi trĩ chiếm 29,4\%, nhưng các búi trĩ đều đẩy lên được, kết quả này cũng tương tự một số kết quả của các tác giả trên thế giới khi mô tả triệu chứng trĩ [5]. Về triệu chứng nghiên cứu gặp chủ yếu các biểu hiện chảy máu nặng với định nghĩa mức độ nặng nhẹ (nhẹ: khi đại tiện ra máu bám vào phân hoặc giấy vệ sinh, vừa: khi đại tiện ra máu nhỏ thành giọt. nặng: khi đại tiện ra máu chảy thành tia), cho thấy bệnh nhân thường đi khám muộn hơn các nghiên cứu khác trên thế giới $[4,6]$. Số lượng vòng cao su sử dụng khi thắt trĩ Các bệnh nhân ở nhóm trĩ nội độ I trung bình được thắt 1.06 lần, ở nhóm độ II trung bình 1.1 lần, ở nhóm trĩ độ III trung bình thắt 1 lần. Số lần thắt trung bình cho 1 bệnh nhân lầ 1.05 lần. Tỷ lệ thành công trong điều trị cầm máu bằng phương pháp thắt trĩ của chúng tôi đạt khá cao 29 bệnh nhân $(85.2 \%)$ cầm máu sau lần thắt thứ 1 , kết quả có tỷ lệ thành công cao so với tác giả khác [4].
Sau khi điều trị thì tất cả các bệnh nhân đều cải thiện chảy máu ngoài tác dụng phụ đau sau thắt đều giảm dần, nó khẳng định hiệu quả của phương pháp điều trị này.

\section{KẾT LUÂ̂N}

Qua nghiên cứu 34 bệnh nhân điều trị trĩ nội có chảy máu bằng phướng pháp thắt vòng cao su có sử dụng máy nội soi ống mềm, chúng tôi nhận thấy rằng đây là phương pháp là hiệu quả và an toàn.

\section{TÀI LIẸU THAM KHẢO}

1. Gearhart, S.L., Symptomatic hemorrhoids. Adv Surg, 2004. 38: p. 167-82.

2. Reese, G.E., A.C. von Roon, and P.P. Tekkis, Haemorrhoids. BMJ Clin Evid, 2009. 2009.

3. Lohsiriwat, V., Treatment of hemorrhoids: A coloproctologist's view. World J Gastroenterol, 2015. 21(31): p. 9245-52.

4. Iyer, V.S., I. Shrier, and P.H. Gordon, Long-term outcome of rubber band ligation for symptomatic primary and recurrent internal hemorrhoids. Dis Colon Rectum, 2004. 47(8): p. 1364-70.

5. Marques, C.F., et al., Early results of the treatment of internal hemorrhoid disease by infrared coagulation and elastic banding: a prospective randomized cross-over trial. Tech Coloproctol, 2006. 10 (4): p. 312-7.

6. Staumont, G., E. Gorez, and J.M. Suduca, [Outpatient treatments of haemorrhoidal disease]. Presse Med, 2011. 40(10): p. 931-40. 